\title{
SAÚDE PÚBLICA E GOVERNOS POSITIVISTAS: os limites da prática*
}

Beatriz Teixeira Weber**

Abstract - The article discuses the public health care in the positivist governments in Rio Grande do Sul in the beginning of the twentieth century. The positivist associate preached the non-intervention in health, but, in practice, they adopted the same measures they criticized.

Os governos gaúchos após a proclamação da República assumiram uma perspectiva positivista, consolidada na Constituição estadual de 1891. Foram influenciados pelos membros do Apostolado Positivista, que realizaram uma intensa divulgação dos seus princípios a nível nacional contra o que acusavam como "despotismo" e "terrorismo sanitário" no final do século XIX e início do século XX. ${ }^{1}$ Um dos

* Este texto é uma versâo modificada de parte do primeiro capítulo da Tese de Doutorado intitulada As artes de curar: medicina, religião, magia e positivismo na República Rio-Grandense - 1889-1928. Campinas: UNICAMP, 1997.

** Professora no Departamento de História da Universidade Federal de Santa Maria, RS, Brasil.

1 Citam-se alguns títulos: MENDES, Teixeira de. O terrorismo sanitário. Rio de Janeiro: Apostolado Positivista do Brasil, 30 abr. 1904; Representação contra a vaccinação obrigatória. Rio de Janeiro: Apostolado Positivista do Brasil, 7 jul. 1904. Ainda em defesa da sociedade contra o despostismo sanitário. Rio de Janeiro: Apostolado Positivista do Brasil, 1920. LEAL, Bagueira. A questāo da vacina. Rio de Janeiro: Sede Central da Igreja Positivista do Brasil, out. 1904. Arquivo da Capela Positivista de Porto Alegre (ACPPA).

Fstudos Ibero-Americanos. PUCRS, v. XXIV, n. 1, p. 131-148, junho 1998 
principais pontos era a discordância contra o "monopólio da medicina" mantido pelos adeptos fanáticos da "medicocracia". Outras discordâncias eram sobre a obrigatoriedade da vacina, a notificação obrigatória dos casos de pacientes com doenças infecto-contagiosas, o isolamento dos pacientes, a desinfecção das casas e a violação dos corpos quando haviam suspeita ou diagnóstico de moléstias contagiosas. Numa dessas publicações, usavam a alegoria de um país imaginado por um romancista francês, León Daudet, chamado "Morticolia". Nesse país imperava o regime "medicocrático" e os médicos teriam ampla ingerência sobre a vida da população. Assim descrevia os países que teriam adotado esse regime, pois ele não seria apenas uma criação do romancista francês:

"Nessas desgraçadas terras, mal nasce uma criança, apresenta-se um médico desconhecido que submete a parturiente aos mais íntimos exames; o leite que tem de alimentar o recém-nascido sofre prolongadas fervuras que lhe tiram as qualidades nutritivas; no sangue dessa criança, como no de toda gente, inocula-se pus com outras substâncias sépticas extraídas de pústulas dos animais; para admissão em institutos de ensino submetem-se moças a vexatórias inspeçôes de saúde, que se registram, como se faz com os recrutas dos exércitos. Encarceram-se impiedosamente cidadãos por simples suspeita do crime de adoecer. Doentes são arrancados do seio de suas famílias e encerrados à força em horríveis prisões que se chamam hospitais de isolamento, em cujas fachadas teria inteiro cabimento a legenda que Dante pôs à entrada do Inferno: 'Deixai toda esperança, oh vós que entrais'.,'

O Brasil seria um dos países ameaçados do perigo de viver sob o regime "medicocrático". Entendiam que tinham que fazer tudo que lhes coubesse para que a "pátria livre" não degenerasse em Morticolia, denunciando o mal que tão funesto regime já estaria fazendo, salientando a irracionalidade e nocividade das práticas descritas acima. A principal função das palestras realizadas pelo Apostolado era concorrer para a formação de uma opinião pública forte, que impedisse a instalação definitiva do regime indigno. ${ }^{3}$

2 LEAL, Bagueira. A segunda conferencia do Dr. Bagueira Leal sobre hygiene pública. Porto Alegre: Off. Graph. da Livraria Brasil, 1921, p. 1 (ACPPA).

3 Idem, p. 2. 
Apesar da intensa campanha contra os princípios do "despotismo sanitário", realizada principalmente no Rio de Janeiro, os membros do Apostolado no Rio Grande do Sul também acabaram sofrendo das "imposições" das medidas sanitárias que eles condenavam, mesmo onde o governo dizia adotar os mesmos princípios que eles defendiam. De modo geral, provavelmente apenas os membros do Apostolado defendiam as orientações positivistas integralmente, inclusive sofrendo críticas dos próprios dirigentes do partido no Estado a respeito do procedimento público adotado. Um episódio envolvendo um membro do Apostolado indica essa divergência. João Luiz de Faria Santos, chefe da seção de Secretaria de Obras Públicas, teve os membros de sua família atacados de varíola. Houve a preocupação do presidente do Estado de intervir pedindo que o sr. Faria Santos permitisse as medidas regulamentares aplicáveis ao caso, que eram o exame do doente por um médico da Higiene para verificar o diagnóstico do médico particular que os assistia, a desinfecção do prédio e o isolamento do enfermo na própria casa com a família ou num lazareto. Faria Santos expressou sua discordância quanto à execução das medidas, inclusive a vacinação de seus filhos, que já havia recusado ao médico que tratava a família. Borges apelou, através desse médico, para a "amizade" que tinha com ele, para que não pusesse dificuldade à ação da Diretoria de Higiene, porque seria desagradável ao Presidente do Estado "[...] o ter de compelir como autoridade a obedecer os seus regulamentos". Faria Santos acabou submetendo-se a contragosto, embora seguidor fiel das propostas do Apostolado. ${ }^{4}$

O episódio deixa clara a adoção de medidas diferentes das apregoadas pelo Apostolado, inclusive obrigando um membro do partido a submeter-se a práticas contrárias aos seus ideais. O próprio Governo Estadual e seu staff não seguiriam rigorosamente os cânones "terapêuticos" positivistas, apesar disso ter efetivamente ocorrido no que se refere à liberdade profissional, defendida como princípio geral. Algumas medidas aparentam ter sido consensuais para os governos estaduais em todo o país no início do século quando ocorriam ameaças de epidemias: a obrigatoriedade da notificação dos órgãos públi$\cos$ a respeito do surgimento de casos de alguma das doenças, o isolamento do doente e a desinfecção das casas com suspeita ou dia-

4 SANTOS, João Luiz de Faria. Contra a diffamação. Artigos a proposito da variola. Porto Alegre: Off. typ. d'A Federação, 1905 (ACPPA). 
gnóstico de moléstias contagiosas. Provavelmente, a pouca informação sobre a propagação das epidemias fazia com que fossem mantidos os únicos procedimentos conhecidos, juntamente com as medidas de saneamento urbano. As medidas adotadas pelos governos positivistas no Rio Grande do Sul resumiam-se ao deslocamento de um médico para o diagnóstico da doença, o isolamento dos doentes ou dos suspeitos e a desinfecção das moradias onde havia se manifestado a doença. Procurou-se observar como eram tratadas as diversas doenças que se manifestaram no Estado.

O coeficiente de mortalidade por mil habitantes manteve-se elevado ao longo de todo o período, principalmente na capital do Estado. Comparando os dados com outras cidades, como Rio de Janeiro, em 1913, por exemplo, cujo coeficiente era de 20,85, ou Londres, de 14,62 , Buenos Aires, de 15,50, Porto Alegre apresentava um elevado índice de mortalidade $(25,70)$. O diretor da higiene do Estado justificava que isso ocorria por falta de medidas higiênicas adequadas e pelo aumento considerável da população na cidade. O coeficiente de mortalidade diminuiria quando ocorressem algumas modificaçōes, que eram apregoadas pelo governo do Estado: o desenvolvimento do serviço de esgotos, a remodelação de algumas áreas da cidade, a demolição de velhos "pardieiros", substituição de prédios urbanos por outros mais ventilados, mais "higiênicos" e, principalmente, o "sensível desenvolvimento" da instrução tornariam a população mais apta para compreender as vantagens das medidas higiênicas e adotá-las. ${ }^{5}$ Algumas das medidas advogadas pelo diretor da higiene só foram tardiamente adotadas em Porto Alegre, como o serviço de esgotos, que já foi indicado, mas as outras propostas mencionadas apenas compunham o discurso defendido pelo partido e não foram implantadas. Apesar dessas considerações, percebe-se uma diminuição gradual do coeficiente dos óbitos por mil habitantes desde $1895 .^{6}$

5 Depoimento do Diretor de Higiene para um estudo na Faculdade de Medicina. LARBECK, Emilio Kemp. A defeza da saude publica no Rio Grande do Sul. Porto Alegre: Off. Graph. de Ildenfonso Robles \& Cia, 1916, p. 17-21. (Biblioteca da Faculdade de Medicina de Porto Alegre/BFMPA).

6 Em 1920 Porto Alegre apresentava um coeficiente de mortalidade de 22,93, em 1925 era de 20,38 e em 1930 era 15,16. Departamento Estadual de Estatística. Sinopse estatistica de Porto Alegre. Porto Alegre: Of. Graf. Livraria do Globo, 1940, p. 28 (BFMPA). 
As doenças que preocuparam os governos no Rio Grande do Sul, a partir de 1895 , foram praticamente as mesmas até 1928 , havendo casos quase todos os anos de difteria, peste bubônica, febre tifóide, varíola, varicela, sífilis e tuberculose. Só adquiriram caráter epidêmico a varíola em 1905 (havendo casos em 1904 e 1906); varicela em 1909 , confundida com varíola; o tifo foi apanágio de quase todas as cidades e vilas, onde reinou endemicamente (o registro é de 1909); em 1918 metade da população do Estado foi atacada de "influenza espanhola" (gripe) (3.971 óbitos); varicela em 1921; “alastrim”, uma varíola atenuada em 1925. Esses foram os casos considerados de "caráter epidêmico" em todo o Estado. Teria havido epidemias localizadas: de peste bubônica em Porto Alegre em 1912 e de varicela em 1917; Rio Grande e Pelotas foram freqüentemente atacadas por varíola e peste bubônica, sem considerar epidemias em cidades menores. Em 1924 o governo afirmou haver profilaxia permanente contra peste bubônica e tifo?

As medidas adotadas em relação às doenças epidêmicas resumiam-se às já descritas. Deslocava-se um médico responsável, faziase a desinfecção de objetos, navios, casas e pessoas, ${ }^{8}$ estabelecia-se o isolamento dos doentes, muitas vezes recolhidos em "hospital flutuante" adquiridos para esse fim em Porto Alegre e Rio Grande." Outras medidas para debelar o mal precisariam do "concurso da higiene privada", que dependia do próprio indivíduo, que devia se submeter ao

7 Mensagens enviadas à Assembléia dos Representantes do Estado do Rio Grande do Sul de 1895 a 1927 e Relatórios apresentados ao Sr. Pres. do Estado do Rio Grande do Sul pelo Secretária de Estado dos Negócios do Interior e Exterior de 1893 a 1929. (Arquivo Histórico do Rio Grande do Sul/AHRS).

\& Houve reclamaçōes do serviço de desinfecção: era tido como agressivo e violento, provocando feridas e machucados nas pessoas que a ela se submetiam. Muitas vezes foram considerados ineficazes porque os funcionários não saberiam usar o equipamento corretamente. O jornal Gazeta do Commercio fez denúncias do mau uso dos aparelhos de desinfecção. "Hygiene. Consideraçōes", 17 nov. 1905, p. 1; "O pessoal da hygiene. Lacuna flagrante", 24 nov. 1905, p. 1. Houve reclamaçôes de queimaduras em virtude da desinfecção: "Variola", 21 jul. 1905, p. 2. O jornal O Dia explicava, em 1894, o que era a desinfecção e seus perigos: 8 dez. 1894. (Museu de Comunicação Social Hipólito José da Costa/MCSHJC).

9 Medidas descritas ao longo de todo o período nos Relatórios da Diretoria de Higiene incluídos nos da Secretaria dos Negócios do Interior e Exterior de 1893 a 1929 (AHRS). 
regime que a medicina prescrevesse. ${ }^{10}$ Medidas específicas foram tomadas em relação à peste bubônica, através da impermeabilização do solo dos prédios, obrigada pela Diretoria de Higiene; visitas domiciliares por fiscais sanitários para verificar o estado dos prédios; juntamente com o isolamento dos doentes e desinfecção dos quarteirões onde surgiram casos. Outra preocupação eram os casos de meningite cérebro-espinhal epidêmica, adotando-se o rigoroso isolamento dos doentes. A lepra preocupava por não existir isolamento dos poucos doentes, que deveria ser feita em colônias de "tipo agrícola" a fim de que tivessem trabalho e distraçōes para amenizar o sofrimento. ${ }^{11}$

Um momento epidêmico significativo foi o da gripe espanhola em 1918. A pandemia difundiu-se pelo mundo a partir do foco dos campos de batalha da Europa, durante a I Guerra Mundial. Em São Paulo, sua voracidade foi comparada com a peste negra medieval pela quantidade de cadáveres e pelo pânico que espalhou. ${ }^{12}$ Chegou a ser chancelada de "inclassificável" devido às graves e variadas complicações que causou, alterando drasticamente a vida da cidade. ${ }^{13} \mathrm{O}$ Rio de Janeiro, segundo a imprensa, teria se transformado num vasto hospital. ${ }^{14}$ A epidemia atingiu o centro do país em outubro, generalizando-se em Porto Alegre em novembro, atacando 70.000 pessoas, numa população de 163.500 habitantes. ${ }^{15} \mathrm{~A}$ epidemia propagou-se rapidamente,

${ }^{10}$ Mensagem enviada à Assembléia dos Representantes do Estado do Rio Grande do Sul pelo presidente Antonio Augusto Borges de Medeiros em 20 de setembro de 1903. Porto Alegre: Off. Typ. d'“A Federação”, 1903, p. 9.

11 Relatório apresentado ao Exmo. Sr. Dr. A. A. Borges de Medeiros Pres. do Estado do Rio Grande do Sul pelo Dr. Protásio Alves Secretário de Estado dos Negócios do Interior e Exterior em 24 de agosto de 1925. Porto Alegre: Off. Graph. d' A Federação", 1925, p. 326-327.

12 SEVCENKO, Nicolau. Orfeu extático na metrópole. São Paulo: Companhia das Letras, 1992, p. 24 e NR 3.

13 BERTUCCI, Liane Maria. Impressões sobre a saúde. A questão da saúde na imprensa operária. Sāo Paulo - 1891/1925. Campinas: UNICAMP, 1992. Dissertação (Mestrado em História) - Instituto de Filosofia e Ciências Humanas, Universidade Estadual de Campinas, 1992, p. 54-55.

14 COSTA, Nilson do Rosário. Lutas urbanas e controle sanitário. Petrópolis: Vozes, 1985 , p. 88.

15 Relatório apresentado ao Exmo. Sr. Dr. A. A. Borges de Medeiros. Pres. do Estado do Rio Grande do Sul pelo Dr. Protásio Alves Secretário de Negócios do Interior e Exterior em 30 ago 1919. Porto Alegre: Off. Graf. d'A Federação, 1919, I vol., p. XVI (AHRS). Departamento Estadual de Estatística. Sinopse estatística de Porto Alegre. Porto Alegre: Of. Graf. Livraria do Globo, 1940, p. 28. 
gerando fortes repercussões. Foi imposta censura à imprensa proibindo a publicação de casos fatais, visando diminuir o estado de "alarme” da população. No Rio de Janeiro foram proibidas também as críticas à atuação da Diretoria Geral de Saúde Pública. No Rio Grande do Sul, as críticas afirmam que deveriam ter sido tomadas medidas que evitassem a disseminação, já que só teria chegado em Porto Alegre dois meses após ter atingido os principais centros. ${ }^{16}$ Apesar da censura, percebe-se nos jornais que não foi feito nada que pudesse evitar a propagação. Lugares de aglomeração de pessoas passaram a ser fechados mais cedo. Faziam o enterro dos mortos, chegando a escalar 16 sentenciados da Casa de Correção para trabalhar nos enterros, pois os coveiros da Santa Casa também ficaram doentes, ou os corpos eram transportados e enterrados à mão pelos próprios familiares das vítimas. Houve reclamações dos preços dos gêneros alimentícios, devido à especulação, que levou o município de Porto Alegre a impor tabelamento dos gêneros de primeira necessidade. O governo teria distribuído alimentação aos pobres. ${ }^{17}$ Pouco se sabia sobre a doença ou como evitar o contágio, gerando pânico e confusão.

Os jornais descreviam as mortes no contexto de quase total ignorância sobre o problema que estavam enfrentando. Elas eram relatadas como conseqüência da gripe. Um exemplo é o caso de um cidadão de Taquara com hemorragia nasal: uma "mosca varejeira" teria "depositado micróbios" no nariz, machucado por causa da "influenza", morrendo com uma "bicheira" no cérebro. Outros casos afirmavam que a febre provocava delírios, o que teria feito que duas senhoras se atirassem em um rio e em um poço. ${ }^{18}$ Como se observa nesses casos, não se sabe a causa das gripes, sendo considerados prejudiciais o frio e as mudanças de clima, pelo perigo de transmissão. Reclamam-se medidas como limpeza das ruas e calhas, desinfecção de prédios e proibição de ajuntamentos. Os "preservativos" seriam a lavagem da boca e garganta com solução de água iodada e um preparado com iodo, "gaiacol, ácido thymico" e álcool, além da lavagem da garganta e das fossas nasais. Os atendimentos foram realizados pelos "licenciados"

16 ESCOBAR, op. cit., p. 213-216.

17 FRANCO, Sérgio da Costa. Porto Alegre: guia histórico. Porto Alegre: Ed. da Universidade/UFRGS, 1988, p. 152-153. Gazeta do Povo, Porto Alegre, 11, 25 nov. 1918, p. 1 (MCSHJC).

18 Gazeta do Povo, Porto Alegre, 11, 18 e 25 nov. 1918, p. 1 (MCSHJC). 
ou pelo que houvesse de gente disponível. ${ }^{19}$ A Escola Médico Cirúrgica de Porto Alegre reuniu todos seus professores, alunos e ex-alunos para atender a população na policlínica da escola e montou um pronto-socorro na sua sede, que funcionou dia e noite de 27 de outubro a 23 de novembro, fornecendo medicamentos gratuitamente, recebidos através da caridade. ${ }^{20}$

A "influenza" era considerada uma moléstia infecciosa devida a micróbios sem identificação, também chamada de gripe, catarro febril, catarro epidêmico e "pequeno correio". Haveria vários tipos. A "nervosa" apresentaria sintomas como catarro, febre, dores no corpo, corrimentos pelo nariz, sonolência, depressão das forças e dores generalizadas de cabeça e ouvido. A "torácica" apresentaria catarro, enquanto a "intestinal" viria acompanhada de vômitos. Atacariam mais as crianças, assim como mais homens que mulheres. Poderia durar dias e até semanas ou meses. O prognóstico não era considerado grave. O tratamento recomendado era repouso no leito, infusões quentes ("borragem" e "sabugueira" eram populares) e "regime dietético". Para dor e febre receitava-se "antipirina", tintura de beladona, sulfato de quinino e xarope de flores de laranjeira. Para tosse haveria outros xaropes e quando houvesse problemas gastrointestinais usavam purgativos. $^{21}$

O Governo tentou acalmar a população distribuindo alimentos conseguidos pela caridade, "estimulando a pobreza a suportar a perda de seus entes queridos". ${ }^{22}$ Única medida efetiva, além do enterro dos mortos. A epidemia registra, antes de tudo, um momento de profunda crise nas condições de existência da população do Rio, São Paulo e de todas as áreas urbanas. No Rio, nem um terço da população escapou de ser atingida. Falta quase absoluta de médicos e serviços de atendimento, crise de abastecimento de meios de subsistência nas cidades, gerando fome que agravava as péssimas condições de vida da população, eram o quadro descrito para os principais centros brasileiros. Revelam uma situação de completa incapacidade das instituições de saúde pública em dar resposta à crise das condições sanitárias da po-

19 Gazeta do Povo, Porto Alegre, 11, 18 e 25 nov. 1918, 20 jan. 1919, p. 1 (MCSHJC).

20 Relatório da Escola Médico Cirúrgica. Porto Alegre: Barcellos, Bertaso \& C., Livr. do Globo, 1918, p. 7. Correspondência Avulsa. 1911-1920 (AHPA).

21 O Dia, Porto Alegre, 3 out. 1894, p. 1 (MCSHJC).

22 Gazeta do Povo, Porto Alegre, 11 nov. 1918, p. 1 (MCSHJC). 
pulação de todo o país. ${ }^{23}$ As atitudes adotadas visavam conter o pânico e aliviar parcamente a tragédia das mortes. No Rio Grande do Sul, a crise não gerou nem uma intervenção específica sobre a doença, nem uma maior preocupação com a questão da saúde pública, mantendo-se o ideário positivista de não intervenção na "liberdade individual", apesar da ameaça visível da epidemia e de ausência de instrumentos adequados ao seu controle.

Apesar de todo esse quadro, a maior responsável pelas mortes no Estado ao longo de todo o período foi a tuberculose. Em 1913 foi mencionada pelos relatórios governamentais como o "flagelo" que parecia acompanhar o crescimento da população. Suas causas seriam o excesso de trabalho, o pauperismo, a intensidade da vida urbana e a insalubridade das habitações. A profilaxia seria resumida à higiene, mediante saneamento do solo e das habitações e a construção de hospitais apropriados. Consideravam que era limitada a ação do poder público para organizar uma cruzada social contra a doença, que carecia ser completada e ampliada pelo "concurso social" e pela "espontânea solicitude e providência moral da mulher", que estaria assumindo, em todos os países, um papel importante nessa luta através da educação doméstica e de conselhos junto ao leito dos doentes. Elogiavam a idéia de uma "Liga contra a Tuberculose" em Porto Alegre, que deveria ser assumida pelo "elemento feminino". ${ }^{24}$

Jornais registram a preocupação de realizar a fundação de um hospital de isolamento de tuberculosos desde 1895 como uma pretensão do Dr. Protásio Alves, Inspetor de Higiene do Estado na época, visando retirar os doentes dos hospitais comuns e colocá-los em estabelecimentos especiais, construídos especialmente para esse fim. A medida era considerada urgente porque havia contaminação nos próprios hospitais onde os pacientes iam curar-se de outras doenças, como atestavam os médicos das enfermarias da Santa Casa de Miseri-

23

24

Mensagem enviada à Assembléia dos Representantes do Estado do Rio Grande do Sul pelo Pres. Antonio Augusto Borges de Medeiros em 20 de setembro de 1913. Porto Alegre: Off. Typ. d'A Federação, 1913, p. 12 e em 20 de setembro de 1914. Porto Alegre: Off. Graph. d'A Federação, 1914, p. 19. Esse discurso é a repetição do Relatório apresentado ao Exmo. Sr. Dr. A. A. Borges de Medeiros Pres, do Estado do Rio Grande do Sul pelo Dr. Protásio Antonio Alves, Secretário de Estado dos Negócios do Interior e Exterior em 8 set. 1914. Porto Alegre: Off. Grap. da Casa de Correcção, 1914, p. 10 (AHRS). 
córdia de Porto Alegre. Além disso, a atmosfera dos hospitais era considerada perniciosa para os tuberculosos, porque precisariam de ar livre e puro. Na Santa Casa pretendiam pôr em execução um pavilhão de tuberculosos na administração da provedoria interina de José Pedro Alves, em 1890, mas nada foi levado a cabo. ${ }^{25}$

O jornal Gazeta do Comércio abriu uma campanha sobre a tuberculose em 1903, para informar à população que a doença era contagiosa, mas curável, devendo-se adotar medidas de higiene que deveriam ser observadas espontaneamente. Tratava dos cuidados com as habitações, das formas de contágio e dos problemas causados pelos escarros dos doentes. Informava que a cura aconteceria com a constante desinfecção dos aposentos, alimentação racional, aeração noturna durante o sono, tonificação do organismo, cuidado com os escarros e persistência na medicação. ${ }^{26}$ As notícias de curas milagrosas sucediam-se, como as que teriam sido obtidas com sucos de vegetais crus, ${ }^{27}$ mas, em geral, todos os jornais tratavam a questão oferecendo receitas e regras de comportamento para que os indivíduos mantivessem a "vitalidade". ${ }^{28}$

A preocupação em abordar a questão da tuberculose ocorreu também em São Paulo, mas não chegou a gerar medidas imediatas. As campanhas antituberculose eram comandadas pelo "altruísmo" dos médicos e das damas da sociedade, porque os serviços oficiais pouco apareciam em relação à doença. Isso destoava do caráter imprimido às campanhas contra a febre amarela, por exemplo, onde os serviços oficiais assumiram por completo a ação sanitária. ${ }^{29}$ No Rio de Janeiro, a prioridade à febre amarela foi ainda mais significativa, sequer mencionando-se a preocupação em abordar a tuberculose. Sidney Chalhoub $^{30}$ argumenta que a opção política de prioridade ao combate à febre amarela, em detrimento da tuberculose, deve-se à opção em

25 Hospitaes de Tuberculosos. O Dia, 15 fev. 1895, p. 1 (MCSHJC).

26 Gazeta do Commércio, Porto Alegre, 4, 17, 20, 24, 28 jul. 1903, 5, 6, 10 e 13 ago. 1903 (MCSHJC).

27 Gazeta do Commercio, Porto Alegre, 31 jul. 1907, p. 2 (MCSHJC).

28 Por que tantos tuberculosos? Folha do Sul, Porto Alegre, 13 dez. 1910, p. 1. Vide Diário de Notícias de 1925 a 1927, onde a questão é uma constante (MCSHJC).

29 RIBEIRO, Maria Alice Rosa. História sem fim... Inventário da saúde pública. op. cit., p. 125-129.

30 CHALHOUB, Sidney. A guerra contra os cortiços: cidade do Rio, 1850-1906, op. cit., p. 42-43. 
viabilizar a entrada maciça de imigrantes europeus no país. Uma das medidas necessárias foi a melhoria das condições de salubridade pública, com ênfase no combate a doenças que, como a febre amarela, ameaçavam principalmente os imigrantes. A população negra apresentava uma certa imunidade à febre amarela. Os órgãos governamentais priorizaram a erradicação das doenças que mais dificultavam a entrada de europeus e o investimento de capitais estrangeiros no país. Já a tuberculose era associada à nutrição e às condições de trabalho e de vida da população, atacando todos indiferentemente e servindo a um discurso moralizador, pois as piores condições de vida eram "restritas" à população mais carente e mais "perigosa" - ou à mais "devassa" e imoral (prostitutas, bêbados, etc.).

No Rio Grande do Sul não se encontrou registro de epidemia de febre amarela, não representando um problema à administração republicana. As maiores preocupações referiam-se ao tifo, peste bubônica e varíola, atacadas com medidas de saneamento urbano, mas sem direção específica ao afastamento da população negra da área central das cidades, provavelmente porque no Estado não havia o mesmo contingente de população negra do Rio de Janeiro. As doenças atacavam indiscriminadamente os imigrantes que vinham ocupar terras no norte do Estado e a população concentrada nos centros urbanos. Com o desenvolvimento da imigração em massa e com os problemas para a ocupação da terra, ${ }^{31}$ muitos imigrantes tomaram o rumo das cidades, onde foram trabalhar, principalmente, na prestação de serviços. A organização de novas relações de trabalho nas áreas urbanas do Rio Grande do Sul incluiu a população negra, nacionais e também a população imigrante. Todos deviam adequar-se ao ideal de trabalho e morigeração, mas a maioria acabava realizando atividades que não exigiam especialização, vivendo em precárias condições, muitas vezes fora dos padrões do "bom trabalhador". ${ }^{32}$ Daí decorre que a preocupação em tratar a tuberculose nunca assumiu o caráter de um trabalho efetivo, mas servia como uma justificativa para denunciar a necessidade de moralização da população pobre.

${ }^{31}$ KLIEMANN, Luiza H. Schmitz. RS: terra \& poder. Porto Alegre: Mercado Aberto, 1986, cap. 1.

32 WEBER, Beatriz Teixeira. "Hierarquizar e regulamentar: a organização do mercado de trabalho no Rio Grande do Sul na segunda metade do século XIX". Estudos Econômicos, v. 24, n. 2. São Paulo: FIPE, maio-ago. 1994, p. 323-324. 
O diagnóstico do bacilo de Koch, responsável pela tuberculose, ocorreu em 1882, contudo o descobrimento de antibióticos que o atacassem só ocorreu em 1944. Até a década de 1940, a tuberculose foi uma das grandes responsáveis pela mortalidade em quase todo o mundo. No final do século XIX e início do XX, o discurso a respeito da doença acusava os próprios pacientes de serem os responsáveis pelos seus males devido à "corrupção dos costumes", não cabendo à sociedade ocupar-se deles. ${ }^{33}$ Além desse discurso moralizador dos mais pobres, acredita-se que o descaso com a doença também tenha ocorrido porque o atendimento da tuberculose no início do século exigia o afastamento do trabalho, com absoluto repouso em lugares de clima ameno (de "bons ares"), por alguns meses, pelo menos. A cura era considerada obra do descanso, do ar oxigenado e da alimentação. Isso só seria possível a pessoas "abastadas", que podiam pagar o repouso em lugares como Campos do Jordão, em São Paulo, São João del Rei ou Belo Horizonte, em Minas Gerais. Aliás, o surgimento de centros de repouso em locais com clima propício ao tratamento de doenças é característico do final do século XIX, início do século XX. A descrição da cura da tuberculose por João Neves da Fontoura, cuja doença foi diagnosticada em 1918, indica o quanto esse tratamento só podia ser realizado por pessoas de "posses". Sua saúde havia se "desgastado" nos invernos do Rio Grande do Sul, sendo tratado de suas gripes sucessivas por um médico da família em Cachoeira, que percebeu a possibilidade da doença. Foi ao Rio de Janeiro para realizar o diagnóstico, que se confirmou através de um exame de laboratório. Seu tratamento foi o indicado acima, tendo se deslocado para São João del Rei, para onde iam os jovens com a doença. Passou lá três meses, sustentado por seu pai, em absoluto repouso, "mesmo do espírito", tendo até sua leitura reduzida aos magazines semanais a conselho médico. A segunda etapa de sua cura realizou-se em Belo Horizonte, onde ficou mais dez meses. Essa cidade era considerada com o clima ideal, ou seja, seco, sem chuvas entre maio e setembro, sol, temperatura estável, um "grande sanatório natural" para a cura. ${ }^{34}$

Vinculada à preocupação com a tuberculose, percebe-se a influência de uma nova perspectiva a respeito de saúde durante a década de

33 GUERRAND, Roger-Henri. Guerra à tuberculose! In: As doenças têm história. Lisboa: Terramar, 1985, p. 187-194.

34 FONTOURA, João Neves da, op. cit., p. 393. 
1920. No caso do Governo estadual, essa nova perspectiva somou-se perfeitamente à visão educativa do PRR. A eugenia passou a fazer parte dos discursos do médico diretor no relatório da Diretoria de Higiene de 1925. Ele afirmava que modernos estudos teriam mostrado que a inoculação do bacilo de Koch se produziria na infância, aconselhando inspeções médicas escolares permanentes e que as escolas e outras atividades das crianças deveriam ser ao ar livre. A base da profilaxia contra a tuberculose deveria ser a higiene infantil, feita “... com critério e rigor para que se consiga a transformação da raça, que, sendo composta de elementos fortes e sadios não mais oferecerá terreno favorável para o desenvolvimento do bacilo de Koch". ${ }^{35}$ Um dos pontos destacados nos estudos eugenistas era a importância das escolas como centros irradiadores de práticas higiênicas moralizadoras e disciplinares. As escolas seriam locais de adestramento através de um projeto médico-pedagógico de higienização do social, inclusive atingindo a educação sexual..$^{36}$

Outros pontos da eugenia destacavam-se no discurso do governo estadual. Deveria ser promovida a educação sanitária do povo, para que aprendesse a se defender da doença e a viver dentro das “... regras da higiene para desfrutar os gozos da vida". ${ }^{37}$ A mortalidade infantil na primeira infância era uma grande preocupação: ocorreria porque as crianças seriam mal alimentadas devido à carestia de vida, tornando os organismos aptos ao desenvolvimento de todos os germes patogênicos. Os problemas teriam origem na vida dos pais das crianças:

"Assim esgotados, combalidos pelo álcool, pela sífilis e pelas moléstias intercurrentes, tais organismos não podem gerar filhos em estado rígido. A criança que já nasce, por via de regra, em

${ }^{35}$ Relatório apresentado ao Exmo. Sr. Dr. A. A. Borges de Medeiros Pres. do Estado do Rio Grande do Sul pelo Dr. Protásio Alves Secretário de Estado dos Negócios do Interior e Exterior em 24 de agosto de 1925. Porto Alegre: Off. Graph. d'“A Federaçāo", 1925, p. XI. Também no Relatório de 1927. Porto Alegre: Off. Graph. d"“A Federaçäo", 1927, p. 539 (AHRS).

36 MARQUES, Vera Regina Beltrāo. A medicalizaçāo da raça: médicos, educadores e discurso eugênico. Campinas: Ed. da UNICAMP, 1994, p. 21 e cap. 3.

37 Relatório apresentado ao Exmo. Sr. Dr. A. A. Borges de Medeiros Pres, do Estado do Rio Grande do Sul pelo Dr. Protásio Alves Secretário de Estado dos Negócios do Interior e Exterior em 24 de agosto de 1925. Porto Alegre: Off. Graph. d' "A Federaçâo”, 1925, p. XI. Também no Relatório de 1927. Porto Alegre: Off. Graph. d'A Federação, 1927, p. 539 (AHRS). 
condições precárias, nem sempre encontra o alimento natural que a mãe não the pode fornecer, ou porque o seu depauperado organismo é incapaz de produzi-lo, ou porque na luta pela subsistência é obrigada a sacrificar os cuidados que deve ao filho"38.

O discurso por parte do Governo insistia no que chamava as "três parcas consumidoras da vida da humanidade": alcoolismo, sífilis e tuberculose. Consideravam que a mais funesta e a mais fácil de ser atacada era a sífilis, com dispensários, cujo objetivo técnico era a propaganda higiênica pelo ensino, tendo por atrativo o tratamento dos doentes. O Governo Federal, associado ao Estado, estabeleceu um dispensário em Porto Alegre, com consulta de 4.903 pessoas, sendo 3.679 atendidos na secção de sífilis no ano de $1925 .{ }^{39}$ Esse discurso também aparece nos jornais, como o Diário de Notícias, onde anunciava os três flagelos sociais que corromperiam a humanidade, o álcool produzindo a degeneração dos órgãos mais nobres, que, junto com a sífilis e a miséria, preparavam o terreno para a tuberculose..$^{40}$ Esse discurso era usado como referência da "sociedade doente", que precisava ser reconstruída para o desenvolvimento de uma nação sadia. O discurso também teve forte influência em São Paulo, compondo um quadro onde era desenvolvida a idéia de cura e "aperfeiçoamento" do homem e da sociedade. ${ }^{41}$

A perspectiva eugenista - leitura radical da teoria evolucionista constituía um ideal político que orientou as práticas de saúde cuja meta era intervir na reprodução das populações. Baseava-se na perspectiva de que não se transmitiriam caracteres adquiridos, sendo as raças resultados imutáveis, e todo o cruzamento entendido como um erro, compreendendo a mestiçagem como sinônimo de degeneração racial e social. O termo eugenia foi criado em 1883 pelo cientista

38 Relatório apresentado ao Exmo. Sr. Dr. A. A. Borges de Medeiros Pres. do Estado do Rio Grande do Sul pelo Dr. Protásio Alves Secretário de Estado dos Negócios do Interior e Exterior em 24 de agosto de 1925. Porto Alegre: Off. Graph. d" A Federação", 1925, p. 328 (AHRS).

39 Idem, p. XI.

40 Um Flagello. Diário de Notícias, Porto Alegre, 25 jul. 1925, p. 1 (MCSHJC).

41 BERTUCCI, op. cit., p. 244. O trabalho analisa como a imprensa operária de São Paulo utilizou os discursos "científicos" sobre a saúde, reapropriando-o em favor dos trabalhadores. Sua análise centra-se em epidemias de peste bubônica, varíola e gripe espanhola, além do tripé que comporia a "sociedade doente": alcoolismo, sífilis e tuberculose. 
inglês Francis Galton, influenciado pela leitura de Charles Darwin, mas o texto considerado fundador da eugenia foi publicado em 1869: buscava provar que a capacidade humana era função da hereditariedade e não da educação. Transformada em um movimento científico e social vigoroso na Europa e Estados Unidos a partir dos anos 1880, sua aplicação visava a produção de "nascimentos desejáveis e controlados", preocupava-se em produzir casamentos entre determinados grupos e desencorajar certas uniōes consideradas nocivas à sociedade. Incentivou uma administração científica e racial da hereditariedade, introduzindo novas políticas sociais de intervenção que incluíam uma deliberada seleção social. ${ }^{42}$

Na década de 1920, no Brasil, proliferaram ligas, associações e entidades civis voltadas para a divulgação dos princípios da eugenia, tendo sido um pioneiro o médico paulista Renato Kehl, que fundou na capital de São Paulo, em 1917, a primeira Liga Eugênica da América do Sul. Foram fundadas por todo o país instituições com essa perspectiva: ligas anti-alcoólicas, de educação sexual, união pró-temperança, dentre outras, propondo a moralização da sociedade e, em particular, dos trabalhadores urbanos ${ }^{43}$. Como prática administrativa, parece ter influenciado a ampliação das atividades dos serviços sanitários, com proteção à infância, inspecção de amas de leite e profilaxia de várias doenças, preocupados com a higiene do trabalho, do alimento, do escolar, da lepra, etc., através da educação, priorizando a "consciência" dos indivíduos. ${ }^{44}$

A visão de eugenia e suas filiaçôes é bastante controvertida nos estudos realizados no Brasil. Alguns autores afirmam que o positivismo foi a teoria que propunha a confiança no futuro do Brasil, contrapondo-se à perspectiva de degenerescência social, que propagaria um pessimismo racial, social e climático do país, fadado a inferioridade

42 SCHWARCZ, Lilia Mortiz. O espetáculo das raças. São Paulo: Companhia das Letras, 1993, p. 58-61.

${ }^{43}$ CUNHA, Maria Clementina Pereira. $O$ espelho do mundo. Rio de Janeiro: Paz e Terra, 1986, p. 166-167.

44 RIBEIRO, op. cit. p. 246-261. IYDA, Massako. Cem anos de saúde pública. A cidadania negada. São Paulo: Editora da Universidade Estadual Paulista, 1994, p. 50-51. MERHY, Emerson Elias. O capitalismo e a saúde pública. 2. ed. Campinas: Papirus, 1987, p. 103. 
racial pela sua formação mestiça. ${ }^{45}$ Nessa visão, o positivismo seria frontalmente contrário à perspectiva eugenista. No entanto, as formas como o positivismo foi mesclado aos interesses de vários defensores da eugenia no Brasil não permitem que se afirme de forma generalizada a incompatibilidade das duas concepções. Uma das escolas que seguiu o positivismo na Europa foi a de Herbert Spencer, na Inglaterra, que também lançou bases de um movimento progressivo da sociedade, aceitando a teoria da evolução de Comte, apesar de negar a sua lei dos três estados e ser contrário à perspectiva religiosa da última fase. João Ribeiro Jr. afirma que essas duas perspectivas apresentam muitos pontos de contato e que a doutrina da evolução social pode se apresentar como doutrina essencialmente positiva. Daí ter sido possível a ideólogos republicanos brasileiros combiná-los, ${ }^{46}$ apesar de haver autores que utilizaram Spencer para combater o positivismo, como foi o caso de Sylvio Romero. ${ }^{47}$ As configurações que o positivismo assumiu no Brasil são bastante diversificadas. Pessoas que se intitulavam positivistas podiam fazer afirmaçóes antagônicas a partir do mesmo ideário, não havendo leituras unívocas de um mesmo conjunto de proposições.

A divulgação dos princípios eugênicos no Brasil ocorreu num contexto de "regeneração da república": de reconstrução e rompimento com os princípios oligárquicos. Sintonizava-se com ideais republicanos dos reformadores para constituir um cidadão ordeiro e inserir o Brasil na "civilização", remodelando o homem brasileiro. Esse processo já teria se iniciado através das políticas higienistas, sendo as tarefas que os eugenistas assumiram seqüência do trabalho dos higienistas. Durante a década de 1920 teriam sido elaboradas as estratégias que tornariam as práticas eugênicas políticas de Estado na década seguinte, encontrando respaldo institucional - legal e autoritá-

45 LUZ, Madel T. Medicina e ordem política brasileira. Rio de Janeiro: Graal, 1982, p. 113. Esse autor baseou-se num texto de STEPAN, Nancy. Gênese e evolução da ciência brasileira. Rio de Janeiro: Artenova, 1976, p. 64. Stepan afirma que um dos primeiros a declarar que a chave do futuro do Brasil estava na ciência foi o médico positivista Pereira Barreto, figura central do movimento de saneamento da cidade de São Paulo na década de 1890.

46 RIBEIRO JR., João. O que é positivismo. 4. ed. São Paulo: Brasiliense, 1985, p. 43-54.

ROMERO, Sylvio. O evolucionismo e o positivismo no Brasil. Rio de Janeiro: 'ivraria Classica de Alves \& C., 1895. 
rio, no governo Vargas, principalmente através de um arcabouço racista. ${ }^{48}$ Nesse contexto, acredita-se que no Rio Grande do Sul, através de médicos diplomados e membros do PRR, parte da perspectiva eugênica foi absorvida. A perspectiva educativa advogada pelos positivistas pode ter favorecido a aproximação com a eugenia, pois ambos defendiam que a população precisava ser "esclarecida". Isso não quer dizer coerência nas medidas propostas, mas que o clima político e o ambiente intelectual também levaram os diretores de higiene a defenderem medidas que podem ser vinculadas à eugenia. Percebe-se uma certa alteração das posições adotadas pela Diretoria de Higiene após 1925, que pode ter se concretizado nas práticas do governo Vargas após 1928, talvez por influência das propostas eugenistas.

Após Getúlio Vargas assumir o governo no Rio Grande do Sul, modificaram-se as bases da organização da saúde. Havia a proposta de um convênio Estado/municípios, onde o Estado realizaria a fiscalização de todo o serviço sanitário e os municípios destinariam parte da sua receita para ser aplicada no serviço sanitário. O Estado organizaria um programa de saúde pública englobando todos os serviços, ampliando a atuação da Diretoria de Higiene. O diretor dr. Fernando F. e Castro avaliava que os serviços sanitários anteriores eram deficientes, sendo necessário unificar tudo que dizia respeito à higiene e saúde pública num mesmo regimento. Faltaria pessoal, aparelhamento, verbas e o próprio código sanitário seria extremamente resumido, tornando impossível qualquer trabalho. As providências tomadas ao iniciar 1929 reuniram as atividades de higiene e saúde pública sob uma mesma direção, criando delegacias de saúde em cada município, subordinadas à Diretoria de Higiene e Saúde Pública do Estado. ${ }^{49} \mathrm{O}$ princípio da "liberdade individual" utilizado para não realizar políticas de intervenção específica sobre práticas de saúde durante os governos anteriores parece ter sido abandonado. A liberdade profissional também foi repensada, tendo sido introduzida uma regulamentação a respeito da prática da medicina no Estado, concretizada na década de 1930.

48 MARQUES, op. cit., p. 20, 44, 60-61, 74, 136.

49 Relatório apresentado ao Dr. Getulio Vargas Pres. do Estado do Rio Grande do Sul pelo Dr. Oswaldo Aranha Secretário de Estado dos Negócios Interiores e Exteriores em 25 ago. 1928. I vol (Secretaria e Repartição Central). Porto Alegre: Off. Graph. d'A Federação, 1928, p. 41-42, 61, 120. Idem em 28 ago. 1929. I vol. Porto Alegre: Off. Graph. d'A Federação, 1929, p. XVIII-XIX (AHRS). 
No período dos governos declaradamente positivistas, as medidas de "saúde pública" priorizadas no discurso foram de saneamento urbano e só foram levadas a efeito durante a década de 1920. As medidas adotadas em caso de doenças epidêmicas eram apenas o isolamento dos doentes, especialmente em lazaretos localizados longe dos centros populacionais, e a desinfecção das residências, medidas com as quais, aliás, os positivistas do Apostolado - mais ortodoxos - não concordavam. Só após 1925 se pode perceber uma outra perspectiva participando do discurso do governo estadual e propondo uma intervenção mais sistemática com fins educativos. Apresentando muitas contradições, positivistas da política e da medicina tentaram afirmar uma perspectiva de saúde marcada por uma sistemática não intervenção. Juntamente com a manutenção do princípio da liberdade profissional, esse contexto permitiu uma ampla presença de práticas de cura diferenciadas, destacando o Rio Grande do Sul como "peculiar" no âmbito das práticas e concepções médicas adotadas na maior parte do país nas primeiras décadas republicanas. 